\title{
POPULATION AGGLOMERATION, ECONOMIC GROWTH AND ENVIRONMENTAL DEGRADATION: EVIDENCE FROM CHINA'S 290 CITIES DURING 2003-2012
}

\author{
WANG, X. X. ${ }^{*}-$ ZHAO, S. S. - CHEN, J. L. \\ Zhejiang University of Finance \& Economics, No.18 Xueyuan St., Hangzhou, China \\ *Corresponding author \\ e-mail: xinxinwang1985@yeah.net \\ phone: + 86-135-8845-8153; fax: +86-571-8673-5886 \\ (Received 13 ${ }^{\text {th }}$ Jan 2017; accepted $23^{\text {rd }}$ Mar 2017)
}

\begin{abstract}
Economic growth and population agglomeration play important roles in environmental degradation. The existing research is primarily concerned with economic growth and the environment, with little attention being devoted to the context of different types of cities and urbanization. This paper attempts to examine the determinants of environmental degradation within the framework of the Human Impact, Population, Affluence and Technology (IPAT) model and further incorporate the variable of population agglomeration based on the Environmental Kuznets Curve (EKC) hypothesis using city-level panel data from 2003 to 2012. Our results indicate that population agglomeration has little or very small impact on environmental degradation, whereas the population size has a positive impact on environmental pollution. The EKC hypothesis is verified with the whole sample of our study; however, the situation varies for different types of cities. The results of this study can serve as a useful reference for policy makers in terms of achieving economic and environmental sustainability.
\end{abstract}

Keywords: urbanization, economic growth, Environmental Kuznets Curve, IPAT model, fixed effects

\section{Introduction}

China has experienced rapid economic growth over the past several decades with an average GDP growth rate of over 9 percent since the reform and opening up policies were first implemented in 1978. China became the world's second largest economy in 2010. In 2014, China's GDP reached 636462.71 yuan (103601.05 in current USD). Meanwhile, China's GDP per capita increased from 381.75 yuan in 1978 to 46652.25 yuan (7593.88 in current USD) in 2014. The average household disposable income reached 20167 yuan in 2014, equal to 3282.71 in current USD (Fig.1). According to the World Bank's classification, China has become an upper-middle income economy. 


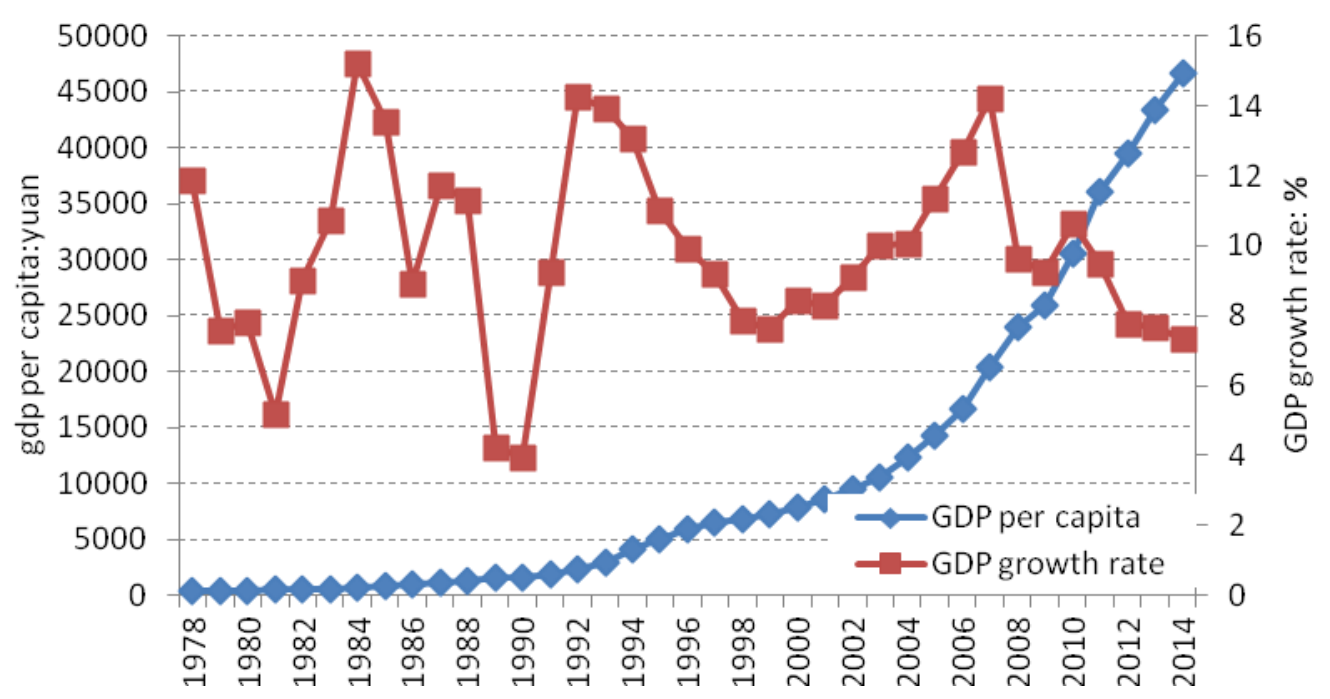

Figure 1. The GDP per capita and GDP growth rate in China (1978-2014)

Data source: China Statistic Year Book (2014); Statistical Bulletin of the National Economic and Social Development (2015); World bank-world development Indicator

Accompanying the development of industrialization and economic growth, since the mid-1980s, China has been witnessed the fastest pace of urbanization in the world. In 2011, China's urban population exceeded the rural population for the first time (Fig. 2). Currently, China has the largest urban population in the world, with 749 million urban dwellers in 2014, accounting for 54.77 percent $^{1}$ of China's total population and 20 percent of the global population.

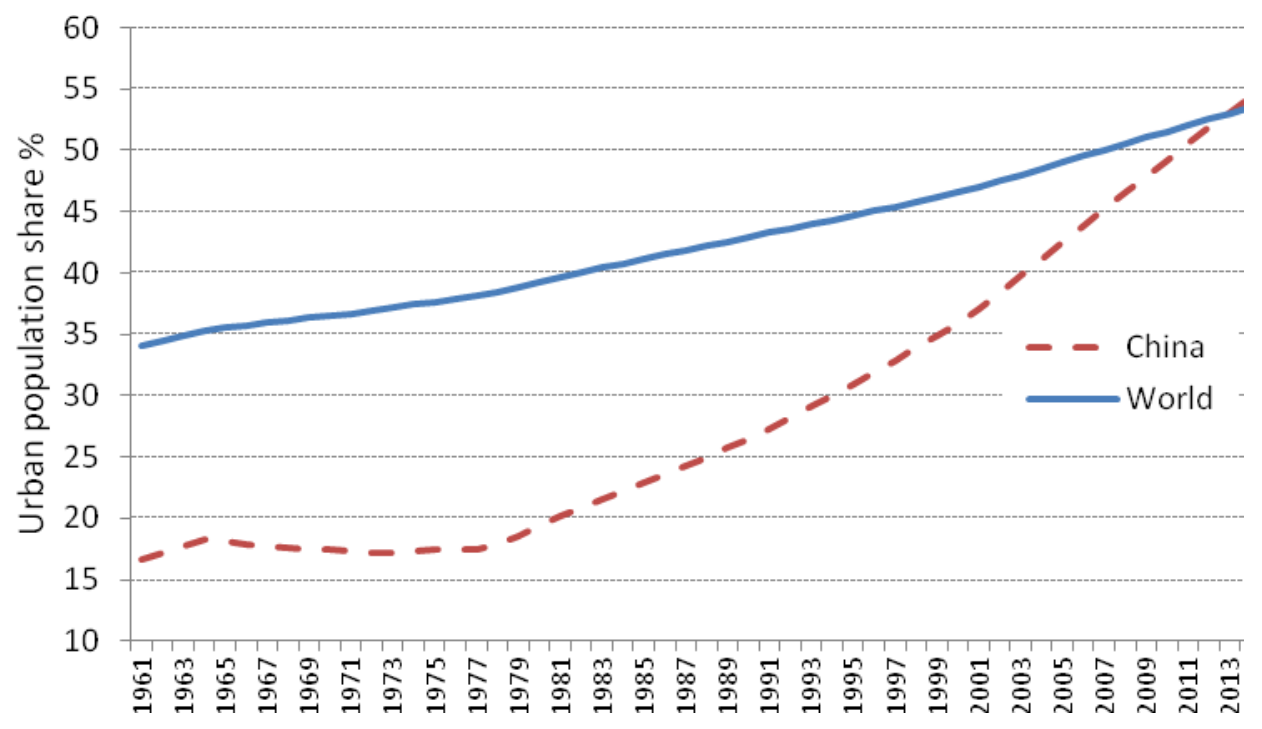

Figure 2. China and the world's urban population share Data source: World Development Indicator, World Bank

\footnotetext{
${ }^{1}$ Data source Feb 26th, 2015.. Statistical bulletin of the national economic and social development http://www.stats.gov.cn/tjsj/zxfb/201502/t20150226_685799.html, accesss on July, 10th. 
However, this impressively rapid economic growth and population agglomeration process has placed abundant stress on environment, which has experienced a large degradation problem. Environmental pollution issues are often front page news and present enormous challenges for China's sustainable development, bringing concern to the central government. For example, the mean annual exposure of PM2.5 air pollution was 72.57 micrograms per cubic meter in China in 2010. The corresponding values for Japan, the UK and the US in 2010 were only $21.81,13.7$, and 13.38 micrograms per cubic meter. In fact, quite a large number of cities in China have reported intense pollution as an air quality problem. What is more, Chinese households have increased demand for environment quality due to rapidly rising incomes. Increasing attention to environment policy has provided renewed stimulus to investigating the relations between population agglomeration, economy and environmental pollution in China. Understanding environmental degradation and its determinants has become increasingly important throughout China.

The nexus between the environment and economic growth has attracted a notably large amount of attention for a long time. A considerable body of literature has examined the relationship between economic growth and environmental degradation. The famous Environmental Kuznets Curve (EKC) hypothesis, which was first proposed by Grossman and Krueger (1991), is defined as a U-shape relationship between economic growth and environmental degradation. The EKC hypothesis posits that environmental pollution will increase with economic growth until a certain income level is reached and then decrease as economic growth proceeds. Soon after this hypothesis was introduced, many empirical studies attempted to test the relationship between economic growth and environmental degradation (Shafik, 1994; Torras and Boyce, 1998; Friedl and Getzner, 2003; Ang, 2007; Saboori et al., 2012; Wang et al., 2015; Apergis and Ozturk, 2015). Most of these empirical studies have verified the EKC hypothesis, although some have not. This discrepancy may because of (1) various research areas, which include global, national, state, provincial, and city levels; (2) different types of data, including time series, panel, and cross-sectional data; and (3) distinct environmental indicators, such as $\mathrm{CO}_{2}$ emissions (Richmond and Kaufmann, 2006; Jaunky, 2010; Saboori et al., 2012; Robalino-López et al., 2015), which is the most popular, as well as $\mathrm{SO}_{2}$ emissions, $\mathrm{CO}$ emissions, water pollution, energy consumption (Suri and Chapman, 1998; Belloumi, 2009; Omri, 2013) and even ecological footprints (Al-mulali et al., 2015).

The relationships between population agglomeration or urbanization and environmental degradation are notably complex (Brennan, 1999). Moreover, the general trend of research regarding this relationship is inconclusive; there is both supporting both a positive and a negative relationship. On one hand, population agglomeration due to the process of urbanization, understood as partly caused by industrialization and economic growth, may have a negative effect on the environment. Some researchers found that the process of urbanization is likely to have a negative impact on the environment (Ángel and Tárraga, 2006; Du et al., 2006; Chen, 2007; Yuan and Zuo, 2011; Zhang and Lin, 2012). On the other hand, the per capita environmental pollution for areas with large population agglomeration may be smaller than that of regions with more dispersed populations. As a 
result, population density and environmental pollution may reveal a negative relationship. For example, Sharif Hossain (2011) tried to incorporated the variable urbanization for a panel of newly industrialized countries and found that urbanization has a significant negative impact on carbon emissions. Therefore, it is difficult to establish a direct link between population agglomeration and environmental problems. Interestingly, some research also tries to examine the impact of environmental change on urbanization. For instance, Barrios et al. (2006) investigated the impact of climate change on the patterns of urbanization in Sub-Saharan African countries with cross-country panel data.

To the best of the author's knowledge, based on the literature review, there is still little focus on the importance of population agglomeration. What is more, as we can see, previous studies indicate that little attention has been paid to city-level panel data, particularly the comparison between different city scales, which are quite different in terms of population agglomeration. Therefore, it is worthwhile to examine population agglomeration, economic growth and environmental degradation.

The rest of the paper is organized as follows. The next section describes the model and data adopted in this study. The estimation and results are demonstrated in the section of "Estimation and Results". Finally, the last section presents the conclusions and policy implications.

\section{Model and Data}

\section{Empirical model}

One of the famous models describing the impact of economic human activity on the environment is the "I= PAT" model, proposed by Ehrlich and Holdren (1971). The formula can be described by equation 1 :

$$
\mathrm{I}=\mathrm{P} \times \mathrm{A} \times \mathrm{T}
$$

Equation 1 indicates that Human Impact (I) on the environment equals the product of $\mathrm{P}$ (population), A (affluence) and $\mathrm{T}$ (technology). This equation describes how growing population, affluence, and technology contribute to environmental impact. Following the framework of IPAT model, Dietz and Rosa (1997) proposed the STIRPAT model, Stochastic Impacts by Regression on Population, Affluence, and Technology, expressed by equation 2 :

$$
I_{i}=a P_{i}^{\alpha} A_{i}^{\beta} T_{i}^{\gamma} e_{i}
$$

In this equation, $\alpha, \beta$ and $\gamma$ are the elasticity of the environmental impact to $\mathrm{P}, \mathrm{A}$ and $\mathrm{T}$, respectively. e denotes the error term, and a is the constant term. Finally, the subscript $\mathrm{i}$ indicates the different regions. Equation 2 can be written in logarithm form as in equation 3: 


$$
\operatorname{LnI} I_{i}=\alpha \ln P_{i}+\beta \ln A_{i}+\gamma \ln T_{i}+\varepsilon
$$

The STIRPAT model has been widely applied to economic and social activity, focusing on the environmental impacts, such as environmental pollution, energy consumption, and the greenhouse effect (Fan et al., 2006; Lin et al., 2009; Wang et al., 2011; Zhang and Lin, 2012). Based on this STIRPAT model, our econometric specification in dynamic panel data terms is represented by model 4 :

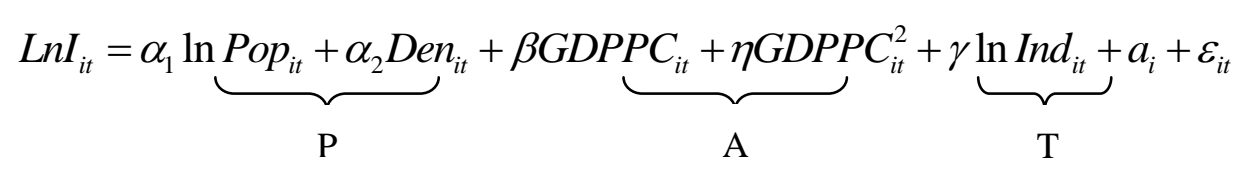

where Pop and Den indicate the population growth and density, respectively, and measure the population. A is measured by GDP per capita (GDPPC) and its square (GDPPC2) on the basis of the EKC framework. The industrial share of GDP (Ind) is used to measure technology, following Zhang and Lin (2012). The subscript i denotes the different cities, whereas $t$ indicates the time period. Equation 4 is a panel model that contains fixed region and time effects.

\section{Measure and data}

This section presents the data sources for our study and introduces details for the explanatory variables as well as the reasons for their inclusion. The panel data used in our study come from provincial and national statistical yearbooks. The final panel data collected in our study include 290 cities from all 31 provinces over the period of 2003-2012, with a total of 2865 observations.

As for the dependent variable, most of the studies use a single indicator, such as $\mathrm{CO}_{2}$ emission, $\mathrm{SO}_{2}$ emission, $\mathrm{CO}$ emission, or water pollution. Several studies adopt composite indicators (such as Jha and Murthy, 2003; Babuand Datta, 2013; Farhani et al., 2014; Wang et al., 2015). Due to data limitations in terms of city-level environmental pollutants, we use a single indicator for the environment variable. The discharged volume of industrial waste water, industrial soot emissions, and industrial $\mathrm{SO}_{2}$ emissions are the only variables that can be collected on the city level. Because industrial soot emissions are more nationwide and more correlated with PM 2.5, which is a large concern among the public, the variable of "industrial soot emissions" is adopted as the dependent variable to measure environmental pollution in our study. Industrial soot emissions vary from a low of 34 tons to a high of 5168812 tons, with a mean of 30155.92 tons and standard deviation of 120056.5 tons. Here, we adopt its logarithm form to reduce the possibility of volatility. For the explanatory variable, the year-end total population is used for the variable of population. The year-end total population varies from 0.164 million, which is a small city, to 33.43 million, which is a super city, with a mean of 4.26 million and standard deviation of 2.9984 million. We also adopt its logarithm to reduce the possibility of heteroscedasticity. The variable density measures the population density on a per 
square kilometer basis. It varies from a minimum 4.7 people $/ \mathrm{km}^{2}$ to a maximum of 2661.54 people $/ \mathrm{km}^{2}$, with a mean of 425.62 and standard deviation of 299.84. GDP per capita, which measures economic growth, is another explanatory variable. It varies from a low of 3.31 ten thousand yuan to a high of 45.03 ten thousand yuan, with a mean of 2.73 ten thousand yuan and standard deviation of 3.31 ten thousand yuan. Finally, the industrial share of GDP has a mean value of 48.87 percent, varying from 9 percent to 90.97 percent. Descriptive statistics, including the mean, standard deviation and minimum and maximum values of the study variables, are given in Table 1.

Table 1. Descriptive statistics of the whole sample

\begin{tabular}{c|c|c|c|c|c|c|c}
\hline Variable & Definition & Unit & Obs & Mean & Std.Dev. & Min & Max \\
\hline Pollution & Dust emission & Ton & 2839 & 30155.92 & 120056.50 & 34.00 & 5168812.0 \\
\hline Population & $\begin{array}{c}\text { Year-end total } \\
\text { Population }\end{array}$ & 10 thousand & 2865 & 425.62 & 299.84 & 16.37 & 3343.40 \\
\hline Density & Population density & People/ $\mathrm{km}^{2}$ & 2862 & 417.17 & 318.68 & 4.70 & 2661.54 \\
\hline GDPPC & GDP Per capita & 10,000 yuan & 2863 & 2.73 & 3.31 & 0.19 & 45.03 \\
\hline $\begin{array}{c}\text { Industrial } \\
\text { share }\end{array}$ & $\begin{array}{c}\text { The share of } \\
\text { industry to GDP }\end{array}$ & Percent & 2863 & 48.87 & 11.48 & 9.00 & 90.97 \\
\hline
\end{tabular}

In addition, the impact of economic development and population agglomeration on pollution emissions may have significant diversity among different city population sizes. Therefore, to quantify the impact of different economic and human activities on environmental pollution among different city sizes, we need additional regression models for various sizes. The latest official criteria for the classification ${ }^{2}$ of city scale by China's State Council is as follows: (1) a small city, with a population under 500 thousand; (2) a middle city, with a population between 0.5 million and 1 million; (3) a large city, with a population between 1 million and 5 million; (4) a megacity, with a population between 5 million and 10 million; and (5) a super city, with a population of over 10 million. In our study, we classified our sample into super cities, megacities, large cities and middle \& small cites based on China's official city classification, with total observations of 110 , 912, 1701 and 124, respectively.

Table 2 shows the descriptive statistics of our sample by city scale. The average population sizes are 12.8731 million, 6.4695 million, 2.7825 million and 0.6615 million, respectively, for super cities, megacities, large cities, and middle- small cities. Further, the population density is also higher for larger cities. For example, the average population density of super cities is 853.52 people per $\mathrm{km} 2$, which is 3.9 times that of middle-small cities. In contrast, GDP per capita exhibited different tendencies with population. Statistics reveal that the middle-small cities had the highest GDP per capita, 45.7 thousand Yuan on average. The mean GDPs per capita for super cities, megacities and large cities are 32.5, 23.9 and 27.5 thousand, respectively. Because the larger cities were more developed in

\footnotetext{
${ }^{2}$ The State Council, 20th, Nov, 2014. Notification on the adjustment of the classification criteria of city scale by China's State Council: http://www.gov.cn/zhengce/content/2014-11/20/content_9225.htm access on 20th Aug, 2015
} 
tertiary industry, the share of industry was relatively low. For instance, the average industry shares of GDP were 45.38 percent, 46.95 percent, 49.40 and 59.57 for super cities, megacities, large cities, and middle-small cities, respectively, in our sample. In terms of industrial soot emissions, super cities had the largest volume of pollution, with an average of 48908 tons per year. The middle-small cities had the smallest volume of pollution ${ }^{3}$, at an average of 15390.79 tons per year. The mean pollution for megacities was slightly smaller than that of large cities. In short, from our statistical analysis, we obtain the following general trends: (1) the larger the population density of a city, the more environmental pollution there will be in that city and (2) the relationship between economic development and environmental pollution is not clear via descriptive statistics. This initial descriptive analysis of our data seems to support some of our expectations. However, a quantitative approach is needed to further explore the precise relationships among agglomeration, economic growth and environmental pollution.

Table 2. Descriptive statistics of the sample by city scale

\begin{tabular}{|c|c|c|c|c|c|c|}
\hline \multicolumn{7}{|c|}{ Super city } \\
\hline Variable & Unit & Obs & Mean & Std.Dev. & Min & Max \\
\hline Pollution & Ton & 110 & 48908.80 & 45023.77 & 2519.00 & 203065.00 \\
\hline Population & 10 thousand & 110 & 1287.31 & 640.47 & 661.07 & 3343.40 \\
\hline Density & People $/ \mathrm{km}^{2}$ & 110 & 853.52 & 481.98 & 379.85 & 2250.68 \\
\hline GDPPC & 10,000 yuan & 110 & 3.25 & 3.30 & 0.24 & 14.14 \\
\hline $\begin{array}{c}\text { Industrial } \\
\text { share }\end{array}$ & Percent & 110 & 45.38 & 8.34 & 22.70 & 57.72 \\
\hline \multicolumn{7}{|c|}{ Megacity } \\
\hline Variable & Unit & Obs & Mean & Std.Dev. & Min & $\operatorname{Max}$ \\
\hline Pollution & Ton & 905 & 30027.09 & 32753.95 & 225.00 & 506490.00 \\
\hline Population & 10 thousand & 912 & 646.95 & 132.63 & 444.68 & 996.40 \\
\hline Density & People/km² & 912 & 542.85 & 300.48 & 117.37 & 2581.78 \\
\hline GDPPC & 10,000 yuan & 912 & 2.39 & 2.38 & 0.24 & 18.54 \\
\hline $\begin{array}{c}\text { Industrial } \\
\text { share }\end{array}$ & Percent & 912 & 46.95 & 8.47 & 22.24 & 66.60 \\
\hline \multicolumn{7}{|c|}{ Large city } \\
\hline Variable & Unit & Obs & Mean & Std.Dev. & Min & $\operatorname{Max}$ \\
\hline Pollution & Ton & 1686 & 30207.24 & 153330.00 & 47.00 & 5168812.00 \\
\hline Population & 10 thousand & 1701 & 278.25 & 100.10 & 82.02 & 656.07 \\
\hline Density & People/km² & 1701 & 336.30 & 272.35 & 10.51 & 2661.54 \\
\hline GDPPC & 10,000 yuan & 1700 & 2.75 & 3.63 & 0.19 & 45.03 \\
\hline $\begin{array}{c}\text { Industrial } \\
\text { share }\end{array}$ & Percent & 1700 & 49.40 & 11.94 & 9.00 & 85.92 \\
\hline
\end{tabular}

\footnotetext{
3 Though the middle \& small cities had relatively higher industrial shares of GDP, the aggregate industrial production was much smaller than that of larger cities.
} 


\begin{tabular}{c|c|c|c|c|c|c}
\hline \multicolumn{7}{c}{ Middle-small city } \\
\hline Variable & Unit & Obs & Mean & Std.Dev. & Min & Max \\
\hline Pollution & Ton & 121 & 15390.79 & 16197.48 & 34.00 & 85442.00 \\
\hline Population & 10 thousand & 125 & 66.15 & 24.50 & 16.37 & 99.10 \\
\hline Density & People/km & 122 & 216.37 & 209.05 & 4.70 & 674.44 \\
\hline GDPPC & 10,000 yuan & 124 & 4.57 & 4.12 & 0.58 & 21.56 \\
\hline $\begin{array}{c}\text { Industrial } \\
\text { share }\end{array}$ & Percent & 124 & 59.57 & 18.37 & 20.60 & 90.97 \\
\hline
\end{tabular}

\section{Estimation and Results}

In this section, we briefly describe our estimation method first and then present our estimation results. There is the possibility of unobserved city-specific effects, which do not change with time, correlated with the dependent variable. Therefore, it is also desirable to control for such individual effects. For these reasons, we adopted both the fixed effects (FE) model and Radom effects (RE) model for our research question. After performing the Hausman test for the FE model and RE model, we rejected the RE model ${ }^{4}$ and considered only the FE model, which is shown in model 1 in Table 3. Because population density and economic growth may have combined effects on environmental pollution, we also add the cross term of population density and GDP per capita in our model (shown in model 2).

From the results of model 1 shown in Table 3, we obtained the following findings: (1) The variables population size, population density, and GDP per capita were all statistically significant in terms of the environmental pollution of industrial soot emissions with the FE models but with different directions. (2) Our empirical results support the EKC hypothesis, showing a reverse "U" shape between economic growth and environmental pollution. The turning point is 138.8 thousand yuan, which indicates that before the GDP per capita arrives at this point, economic growth and industrial soot emissions have a positive relationship. After arriving at this point, the relationship turns negative. However, in our sample observation, GDP per capita after the turning point accounts for only 1.675 percent, which means that the square of GDP per capita can be neglected in our study. (3) The year-end total population has a positive estimated coefficient, whereas population density has a negative estimated coefficient. These results indicate that the total population size leads to increased environmental pollution, whereas the reverse is true for population density. The economic interpretation of the results of the main specification is that when all control variables are included, if the total population increases by 1 percent, the total industrial soot emissions increase 0.61 percent. In contrast, the negative estimated coefficient for population density is very small, only -0.0004 . Therefore, we can almost ignore the negative impact of population density. (4) Finally, the variable of industrial share is insignificant in regression model 1.

\footnotetext{
4 The resutls of Hausman test for RE and FE models is chi2 $(6)=(b-B)^{\prime}\left[\left(V \_b-V \_B\right)^{\wedge}(-1)\right](b-B)=65.29$; Prob $>$ chi $2=0.0000$, which indicate the rejection of original hypothesis for RE model.
} 
Table 3. Estimation results for the whole sample with the fixed effects model

\begin{tabular}{c|c|c|c}
\hline Variables & Model 1 & Model 2 & Model 3 \\
\hline \multirow{2}{*}{ lnpop } & $0.606 * *$ & $0.622^{* *}$ & $0.623^{* *}$ \\
& $(2.14)$ & $(2.19)$ & $(2.2)$ \\
\hline \multirow{2}{*}{ Density } & $-0.0004 * *$ & $-0.0004 * *$ & -0.0003 \\
& $(-1.99)$ & $(-2.29)$ & $(-1.54)$ \\
\hline \multirow{2}{*}{ GDPPC } & $0.040^{* * *}$ & 0.01 & $0.109^{* * *}$ \\
& $(3.44)$ & $(1.35)$ & $(3.42)$ \\
\hline \multirow{2}{*}{ GDPPC ${ }^{2}$} & $-0.001 * * *$ & - & - \\
\hline \multirow{2}{*}{ Industry } & $(-3.35)$ & $0.006^{* *}$ & $0.005^{*}$ \\
& 0.004 & $(2.37)$ & $(1.75)$ \\
\hline \multirow{2}{*}{ Dens GDPPC } & $(1.25)$ & - & $-0.017 * * *$ \\
& - & $5.922^{* * *}$ & $5.935^{* * *}$ \\
\hline \multirow{2}{*}{ Constant } & $6.073 * * *$ & $(3.73)$ & $(3.74)$ \\
\hline Observation & $(3.83)$ & 2837 & 2837 \\
\hline
\end{tabular}

Note: "*", "**", and "***"denote significance at the $10 \%, 5 \%$ and $1 \%$ levels, respectively.

We drop the square of GDP per capita in our model 2 and obtain similar results for population and population density. In contrast, the variable for industrial share is significant in regression model 2 , with a positive estimated coefficient of 0.006 , which means a 1 percent increase in the industrial share results in a 0.6 percent increase in industrial soot emissions. In addition, the GDP per capita is no longer significant in this model. Considering that population agglomeration and economic growth have combined effects on environmental pollution, we introduce the cross term of population density and GDP per capita in model 3. GDP per capita and the cross item of GDP per capita and population density are strongly significant in model 3 , whereas density itself is no longer statistically significant. The economic interpretation of this result is that economic growth and population density have a combined impact on environmental pollution. More specifically, at the average population density, which is 417.17 people per $1 \mathrm{~km}^{2}$, the coefficient for the impact of GDP per capita on industrial soot emissions is $-6.85^{5}$.

To further explore the variation in environment impact for different city sizes, the four types of city samples are run independently. The estimation results for super cities, megacities, large cities, and middle-small cities with the FE panel model are shown in Table 4. From the estimation results, we find that the effect of population on environmental pollution is quite different among the various types of cities. Mainly, we obtain the following findings: (1) In terms of demographic characteristics, population

\footnotetext{
$5.1089906-.0166714 * 417.17=-6.8458173$
} 
density is insignificant for all four types of cities, which indicates that population agglomeration may not result in environmental degradation. However, it may have an indirect impact on the environment via other variables such as economic growth. Only the year-end population size of megacities and large cities has a significant and positive effect on environmental pollution. More specifically, a 1 percent increase in population size would result in a 1.6 percent and 1.02 percent increase in soot emissions for megacities and large cities, respectively. (2) The results for economic growth (proxied by GDP per capita) are interesting. The variable of GDP per capita and its square are significant only for super cities and large cities. Interestingly, the estimated coefficients for super cities and mega cities have different signs as those for large cities and middle-small cities. For super cities, the variable of GDP per capita is significant and negative, whereas its square is significant and positive. Thus, economic growth and environmental pollution have a U-shape relationship, with a turning point of $71,755.6^{6}$ yuan per person. However, only 13 observations are past this turning point, or 11.8 percent of the total sample for super cities. Altogether, this finding further indicates that economic growth and environmental pollution have a negative relationship for super cities. Though the estimated coefficient is not significant for mega cities, they have the same impact direction as super cities. The situation is different for large cities and middle-small cities, the estimated coefficients of which have the opposite signs. For large cities, GDP per capita has the standard positive and significant estimated coefficient, whereas the square of GDP per capita is negative and significant. Thus, for large cities, there is a U-shape relationship between economic growth and environmental pollution with a turning point of $141,269.8^{7}$ yuan per person. However, only a 2 percent share of the sample is past this turning point, which means the relationship between economic growth and environmental pollution is positive for large cities. (3) The variable of industrial share is significant for all four types of cities but with different effects. Different from the whole sample, the industrial share of GDP is statistically significant for all types of cities. However, megacities have a standard negative estimated coefficient of -0.013 , which indicates that industrial share and environmental pollution have a negative relationship. For all three other types of cities, the relationship between industrial share and environmental degradation is positive.

Table 4. Estimation results for the different city types with the fixed effects model

\begin{tabular}{c|c|c|c|c}
\hline Variables & Super city & Megacity & Large city & Middle- Small city \\
\hline \multirow{2}{*}{ lnpop } & -1.624 & $1.598 * *$ & $1.020 * * *$ & -1.302 \\
& $(-1.32)$ & $(2.32)$ & $(2.81)$ & $(-1.01)$ \\
\hline \multirow{2}{*}{ Density } & 0.0003 & -0.0001 & -0.0004 & -0.001 \\
& $(0.42)$ & $(-0.46)$ & $(-1.59)$ & $(-0.88)$ \\
\hline
\end{tabular}

\footnotetext{
$6.3429042 / 2 / .0238939=7.1755595$;

$7.0551037 / 2 / .0019503=14.12698$
} 


\begin{tabular}{c|c|c|c|c}
\hline \multirow{2}{*}{ GDPPC } & $\begin{array}{c}-0.343 * * * \\
(-3.58)\end{array}$ & $\begin{array}{c}-0.052 \\
(-1.46)\end{array}$ & $\begin{array}{c}0.055^{* * *} \\
(3.53)\end{array}$ & $\begin{array}{c}0.085 \\
(1.58)\end{array}$ \\
\hline \multirow{2}{*}{ GDPPC $^{2}$} & $0.024 * * *$ & 0.002 & $-0.002^{* * *}$ & -0.0004 \\
& $(4.22)$ & $(1.08)$ & $(-3.79)$ & $(-0.20)$ \\
\hline \multirow{2}{*}{ Industry } & $0.050 * * *$ & $-0.013 * *$ & $0.007 *$ & $0.022^{*}$ \\
& $(3.14)$ & $(-2.51)$ & $(1.87)$ & $(1.83)$ \\
\hline \multirow{2}{*}{ Constant } & $19.900 * *$ & 0.412 & $3.613 *$ & $12.826^{* *}$ \\
& $(2.5)$ & $(0.10)$ & $(1.86)$ & $(2.46)$ \\
\hline \multirow{2}{*}{ Observation } & 110 & 905 & 1685 & 120 \\
\hline
\end{tabular}

Note: "*", "**", and "***"denote significance at the $10 \%, 5 \%$ and $1 \%$ levels, respectively.

\section{Discussions and Policy Implication}

This paper tries to examine the determinants of environmental degradation within the framework of IPAT model and further incorporate the variable of population agglomeration. This study also attempts to distinguish the different impacts at different city scales. The results of this empirical study have several profound implications.

First, although statistical data show that the larger the population density of a city, the more environmental pollution there will be in that city, through our quantitative empirical analysis, we find that population agglomeration has a small to very small impact on environmental degradation. Density in cities is accompanied by a larger urban population. This result may not be consistent with some studies claiming that "the process of urbanization is likely to have a negative impact on environment". However, this finding is reasonable and acceptable. Higher population agglomeration may also yield higher economic agglomeration. Numerous dense cities are classified as super cities, which have higher economic development and relatively higher tertiary industrial shares. Consequently, the environmental pollution will be smaller than in other less developed regions. For example, Shanghai, the largest super city in China, has a population density of 3809.15 person per kilometer (in 2013), which is 27 times China's average, with an urban population share of 89.6 percent and tertiary industrial share of 62.24 percent(see Table 5). The other reason is that more developed regions in China have higher production costs (such as labor costs and rental costs), and some heavily polluting industries move to less developed regions, which may result in more serious pollution problems in these less developed areas. Therefore, our results show that population density even has a negative relationship with environmental pollution. This finding is consistent with that of Sharif Hossain (2011), who found that urbanization has a significant negative impact on carbon emissions. However, our results demonstrate that population density has only a small impact on environmental pollution. More specifically, if the population density increased by 100 people per square kilometers, the industrial soot emissions would decrease by 4 percent based on our results. 
Table 5. Population and economic characteristics in the year 2013

\begin{tabular}{|c|c|c|c|c|c|c|}
\hline Region & $\begin{array}{c}\text { Total } \\
\text { population }\end{array}$ & $\begin{array}{c}\text { Population } \\
\text { density }\end{array}$ & $\begin{array}{c}\text { Urban } \\
\text { population } \\
\text { share }\end{array}$ & $\begin{array}{c}\text { Industry } \\
\text { share }\end{array}$ & $\begin{array}{c}\text { Service } \\
\text { Share }\end{array}$ & $\begin{array}{c}\text { GDP per } \\
\text { Capita }\end{array}$ \\
\hline Unit & 10 thousand & person $/ K M^{2}$ & $\%$ & $\%$ & $\%$ & Yuan \\
\hline Shanghai & 2415 & 3809.15 & 89.6 & 37.16 & 62.24 & 93213 \\
\hline Beijing & 2115 & 1289.63 & 86.3 & 22.32 & 76.85 & 90092 \\
\hline National & 136072 & 140.86 & 53.73 & 43.89 & 46.09 & 41908 \\
\hline
\end{tabular}

Data source: China Statistics yearbook (2014); Shanghai Statistics yearbook (2014); Beijing Statistics yearbook(2014)

Second, the population size has a positive impact on environmental pollution. In addition, only megacities and large cities have significant effects from our empirical results. A larger population may not lead to a higher population density. For example, China's largest population province, Henan, has a total population of 90.82 million people, accounting for 7.48 percent of China's total population, but only 43.9 percent of the population was in urban area in 2013, almost 10 percent lower than China's average national level. According to the latest air quantity report released by the Ministry of Environmental Protection on 17 th August, $2015^{8}$, Henan's provincial capital city, Zhengzhou, is one of the most polluted cities. Generally, our results show that a one percent increase in population for a city equates to a 0.6 percent increase of soot emissions in the city. Additionally, the situation is more serious for megacities and large cities, with estimated coefficients of 1.60 and 1.02, respectively. During the process of urbanization and industrialization, the local government should not only focus on GDP growth as the final goal of city development but also pay more attention to the functions of the city and environmental protection for future generations.

Third, our empirical results with the whole sample data verified the theory of the EKC hypothesis, which shows a reverse "U" shape between economic growth and environmental pollution. However, the share of our observations with a GDP per capital exceeding the U-shape turning point is only 1.675 percent, which can be ignored. This result further indicates that economic growth and environmental pollution present a negative relationship based on our panel data. This is because the research period is between 2003 and 2012, during which China's rapid economic growth was accompanied by increasingly severe environmental degradation. We should note that though our result shows a U-shape relationship between economic growth and environmental pollution, the environmental quality will not be improved automatically without any protection. With the rapid rise in household income due to the fast development of China's economy, the public is becoming more concerned about environmental quantity. In addition, the government has the ability to manage environmental issues with increased fiscal revenue

\footnotetext{
${ }^{8}$ Ministry of Environmental Protection.17th, Aug,2015."The urban air quality of key area and 74 cities in July." http://www.zhb.gov.cn/gkml/hbb/qt/201508/t20150817_308235.htm, access on 5th,Sep,2015.
} 
from economic growth. Thus, the government should pay more attention to the management and protection of the environment and adjust the economic industry structure with, e.g., the development of service sectors. In fact, for most of the developed countries, the GDP share of the service sector is much higher than the industrial share. For example, the average shares of agriculture, industry and services for high-income countries are 1.58 percent, 24.59 percent and 73.84 percent, ${ }^{9}$ respectively, in 2013 . For the United States, in 2013, the three sectors' shares were 1.45 percent, 20.50 percent and 78.05 percent $^{10}$, respectively. In contrast, in China, the shares of agriculture, industry and services were 9.17 percent, 42.64 percent and 48.19 percent respective in $2014^{11}$. China still has a long way to go in terms of adjusting its economic structure.

Fourth, when referring to the city scale, our research reveals that the relationship between economic growth and environmental degradation is different for various types of cities. Specifically, economic growth and environmental pollution show a negative relationship for larger cities such as super cities and megacities and a positive relationship for relatively smaller cities, such as large cities and middle and small cities. Based on cross-sectional data, different types of cities experience different process of economic development. Generally, the larger the city population is, the more economic agglomeration there will be. The most developed cities have higher development of tertiary industry and less environmental pollution. China may still have a long way to go in terms of managing environmental issue, and local governments should not sacrifice the environment during economic development.

Acknowledgements. This paper is one of the outcomes of Zhejiang Major Project in Humanities and Social Science Research Projects (2013QN046)--The Impact of Urbanization on Household's Income Distribution in Zhejiang. We are grateful to Qing Yu and Shengnan Deng for helping collect the data from China Statistic Yearbook, Zhejiang Statistic Yearbook, CAMAR database and wind database and for their capable research assistance. We would like to acknowledge the support from Natural Science Foundation of China 71403236.We would also like to acknowledge the valuable suggestions from Langshan Shu and Xuanzi Peng during the preparation of the earlier draft.

\section{REFERENCES}

[1] Al-mulali, U., Weng-Wai C., Sheau-Ting, L., Mohammed, A. (2015): Investigating the environmental Kuznets curve (EKC) hypothesis by utilizing the ecological footprint as an indicator of environmental degradation. - Ecological Indicators 48: 315-323.

[2] Ang, J.B. (2007): $\mathrm{CO}_{2}$ emissions, energy consumption, and output in France. - Energy Policy 35: 4772-4778.

[3] Angel, M., Tárraga, O. (2006): A conceptual framework to assess sustainability in urban ecological systems. - Int. J. Sustain. Dev. World 13 (1): 1-15.

[4] Apergis, N., Ozturk, I. (2015): Testing Environmental Kuznets Curve hypothesis in Asian countries. - Ecological Indicators 52: 16-22.

[5] Barrios, S.; Bertinelli, L.; Strobl, E. (2006): Climatic change and rural-urban migration:

\footnotetext{
${ }^{9}$ Data source: World Development Indicator; World Bank.

${ }^{10}$ Data source: World Development Indicator; World Bank.

11 Data source: Statistical Bulletin of National Economic and Social Development, 2015 edition.
} 
The case of sub-Saharan Africa. - Journal of Urban Economics 60 (3): 357-371.

[6] Belloumi, M., (2009): Energy consumption and GDP in Tunisia: cointegration and causality analysis. - Energy Policy 37: 2745-2753.

[7] Brennan, E. M. (1999): Population, Urbanization, Environment, and Security: A Summary of the Issues. - ENVIRONMENTAL CHANGE \& SECURITY PROJECT REPORT(ISSUE 5).

[8] Chen, J. (2007): Rapid urbanization in China: A real challenge to soil protection and food security. - CATENA 69 (1): 1-15.

[9] Dietz, T., Rosa, E.A.(1997): Effects of population and affluence on CO2 emissions. Proceedings of the National Academy of Sciences of the United States of America 94: $175-179$.

[10] Du, B., Zhang, K.M., Song, G.J., Wen, Z.G.. (2006): Methodology for an urban ecological footprint to evaluate sustainable development in China. - Int. J. Sust. Dev. World 13 (4): 245-254.

[11] Ehrlich, P.R., Holdren, J.P. (1971): Impact of population growth. - Science 171:1212-1217.

[12] Fan, Y., Liu, L., Wu, G., Wei, Y. (2006): Analyzing impact factors of CO2 emissions using the STIRPAT model. - Environmental Impact Assessment Review 26:377-395.

[13] Fan, Y., Liu, L., Wu, G., Wei, Y. (2006): Analyzing impact factors of CO2 emissions using the STIRPAT model. - Environmental Impact Assessment Review 26:377-395.

[14] Friedl, B., Getzner, M. (2003): Determinants of CO2 emissions in a small open economy. - Ecol. Econ. 45: 133-148.

[15] Grossman, G.M., Krueger, A.B. (1991): Environmental impacts of a North American Free Trade Agreement. - National Bureau of Economic Research Working Paper 3914. NBER, Cambridge, MA.

[16] Jaunky, V.C. (2010): The $\mathrm{CO}_{2}$ emissions-income nexus: evidence from rich countries. Energy Policy 39: 1228-1240.

[17] Omri, A. (2013): CO2 emissions, energy consumption and economic growth nexus in MENA countries: Evidence from simultaneous equations models. - Energy Economics(40): 657-664.

[18] Richmond, A.K., Kaufmann, R.K. (2006): Is there a turning point in the relationship between income and energy use and/or carbon emissions? - Ecol. Econ. 56: 176-189.

[19] Robalino-López, A., Mena-Nieto, Á., et al. (2015): Studying the relationship between economic growth, $\mathrm{CO}_{2}$ emissions, and the environmental Kuznets curve in Venezuela (1980-2025). - Renewable and Sustainable Energy Reviews 41: 602-614.

[20] Saboori, B., Sulaiman, J., Mohd, S. (2012): Economic growth and CO2 emissions in Malaysia: a cointegration analysis of the Environmental Kuznets Curve. - Energy Policy 51:184-191.

[21] Shafik, N. (1994): Economic Development and Environmental Quality: An Econometric Analysis Author(s): Nemat Shafik Source: Oxford Economic Papers, New Series, Vol. 46, Special Issue on Environmental Economics: 757-773.

[22] Sharif Hossain, M. (2011): Panel estimation for CO2 emissions, energy consumption, economic growth, trade openness and urbanization of newly industrialized countries. Energy Policy 39 (11): 6991-6999.

[23] Suri, V., Chapman, D. (1998): Economic growth, trade and energy: implications for the environmental Kuznets curve. - Ecological Economics 25 (2): 195-208.

[24] Torras, M., Boyce, J. K. (1998): Income, inequality, and pollution: a reassessment of the environmental Kuznets Curve. - Ecological Economics 25 (2): 147-160.

[25] Wang, L., Zhou, D., Wang, Y., Zha, D. (2015): An empirical study of the environmental Kuznets curve for environmental quality in Gansu province. - Ecological Indicators 56: 96-105. 
[26] Wang, M., Che, Y., Yang, K., Wang, M., Xiong, L., Huang, Y. (2011): A local-scale lowcarbon plan based on the STIRPAT model and the scenario method: the case of Minhang District, Shanghai, China. - Energy Policy 39: 6981-6990.

[27] Yuan, X.L., Zuo, J. (2011): Transition to low carbon energy policies in China- from the Five-Year Plan perspective. - Energ. Policy 39 (6): 3855-3859.

[28] Zhang, C., Lin, Y. (2012): Panel estimation for urbanization, energy consumption and $\mathrm{CO}_{2}$ emissions: A regional analysis in China. - Energy Policy 49: 488-498. 